\title{
The effects of compassion experienced by SME employees on affective commitment: Double-me- diation of authenticity and positive emotion
}

\author{
Sung-Hoon Ko ${ }^{\mathrm{a}}$ and Yongjun $\mathrm{Choi}^{\mathrm{b}^{*}}$
}

${ }^{a}$ Graduate School of Education, Kyonggi University, South Korea

${ }^{b}$ College of Business Administration, Hongik University, Seoul, South Korea

\section{H R O N I C L E}

Article history:
Received: September 25, 2019
Received in revised format: No-
vember 192019
Accepted: November 19, 2019
Available online:
November 19, 2019
Keywords:
Compassion
Authenticity
Positive emotion
Affective commitment

\section{A B S T R A C T}

\begin{abstract}
The purpose of this study is to empirically examine the effects of compassion experienced by smallto-medium enterprise (SME) employees on affective commitment through authenticity and positive emotion. This study was conducted with 200 employees working at SMEs located in South Korea. The results show that the relationships between compassion and authenticity, between authenticity and positive emotion, between positive emotion and affective commitment, and between compassion and affective commitment were significant. In addition, the relationship between compassion and affective commitment was significantly double-mediated by authenticity and positive emotion. The results provide a meaningful implication that SME employees would build authenticity and positive emotions by experiencing compassion and that those who build authenticity and positive emotions would enhance their affective commitment.
\end{abstract}

\section{Introduction}

The organizational members' compassions occur as an act of responding to the physical and mental suffering of colleagues, subordinates, and supervisors or to the suffering caused by interpersonal relationships between colleagues and between supervisors and subordinates. Suffering can be defined as experiencing distress that causes ontological bitterness (Reich, 1989). Such suffering may be stimulated by illness or injury, death of a loved one, and mental trauma that could occur at the workplace (Harvey, 2001). This personal empathy acts as a source of caring and healing for other struggling members of the organization (Dutton et al., 2002; Wuthnow, 1991). After the 9/11 terrorist attacks in 2001, Dutton and his colleagues formed the Positive Organizational Scholarship (POS) and have actively conducted research on compassion, positive emotion, positive work-related identity, job crafting, etc. Their research on compassion has mainly relied on qualitative approaches, case studies to be specific, and Lilius et al. (2008) have developed compassion scales to apply in their research. Conducting a study on compassion, Moon et al. (2014) found the positive relationship between corporate social responsibility (CSR) and compassion, and Hur et al. (2016) found the positive effects of compassion and positive work-related identity on performance variables. Empirical studies on compassion, qualitative or quantitative, have consistently increased since Lilius et al. (2008) conducted an empirical study on the causal relationships among compassion, positive emotion, and affective commitment. To advance the previous qualitative and/or quantitative studies on compassion within an organization, this study empirically examined how compassion experienced by SEM employees would be associated with affective commitment through authenticity and positive emotion.

\footnotetext{
* Corresponding author.

E-mail address: yongjun.choi@hongik.ac.kr (Y. Choi) 
Therefore, this study provides an implication that when SME employees, who are known to have a high level of job stress and emotional exhaustion, share compassion in their organization, they feel authenticity and build positive emotions about their organization, which eventually lead to a stronger affective commitment to their organization. That is, this study practically suggests that if SME employees experience compassion as an act of caring in response to the suffering of others, they would feel authenticity about the experienced compassion and form positive emotions with other employees and thereby make a stronger affective commitment to their organization.

\section{Conceptual framework}

\subsection{Compassion and authenticity}

Compassion means not only the 'high-quality connection' (HQC) with others but also the act of caring in response to the suffering of others in terms of cognitive, emotional, and behavioral dimensions; it is distinguished from other emotions in that it entails acts of reaction to the suffering (Dutton et al., 2002; Frost et al., 2000; Solomon, 1998). Compassion experienced by members within an organization is manifested as acts of responding to not only the mental and physical suffering experienced by colleagues, subordinates, and supervisors but also the suffering arising from interpersonal relationships among organizational members. Terms similar to compassion include sympathy, projection, and identification. Sympathy refers to the transfer of others' feelings to myself; projection means the transfer of my feelings into others, and identification indicates feeling a sense of oneness with others (or others' feelings) or the organization. Research on compassion has been actively conducted since 1990, and Dutton at the University of Michigan's POS has been at the center of the research. Researchers at the POS claim that compassion represents a state of emotion that expresses a warm heart, courtesy, and authentic act of caring, regardless of any presumptuous motive (Dutton et al., 2002). Compassion is also a relational process entailing good deeds that help to recognize the suffering of others, sympathize with their mental suffering, and reduce the suffering (Solomon, 1998). Therefore, when SME employees experience mental and physical distress due to job stress and emotional exhaustion at their workplace, they are likely to show authentic behaviors based on the affect control theory (Grandey, 2003). Because compassion is a relational process that pays attention to the suffering of others, results in empathy with the suffering, and triggers an authentic behavior to relieve the suffering in some way, SME employees experiencing compassion are expected to show authentic behaviors (Kanov et al., 2004). Miller (2007) regards organizational members' compassion as an emotional work with authenticity that occurs naturally in mind, not as an emotion caused by artificial effort. In other words, organizational members experiencing compassion would feel it as an authentic behavior because compassion as an emotional work means that organizational members support each other genuinely and voluntarily from the bottom of their hearts. Therefore, based on previous studies on the relationship between compassion and authenticity and on the affect control theory, this study set the following hypothesis:

\section{$H_{1}$ : Compassion experienced by SME employees is positively associated with authenticity.}

\subsection{Authenticity and positive emotion}

Previous studies on authenticity and positive emotion emphasized the importance of emotion (Ashkanasy \& Tse, 2000; Michie \& Gooty, 2005). Some studies on authenticity revealed that authenticity enhanced positive emotion (Walumbwa et al., 2008; Avolio \& Mhatre, 2012). The causal relationship between authenticity and positive emotion can be explained by the emotional contagion mechanism. Emotional contagion is a process of social influence in which an individual or organization affects an emotional state or behavior (Schoenewolf, 1990; Barsade, 2002). Ilies et al. (2005) suggest that organizational members who feel authenticity are likely to experience positive emotion through positive self-awareness and high-quality connection (HQC) based on emotional contagion. Accordingly, the stronger the feeling of authenticity, the stronger the experience of positive emotion. Furthermore, authenticity promotes positive interpersonal relationships among supervisors, subordinates, and colleagues (Walumbwa et al., 2008). Such positive interpersonal relationships can be a driving force and motive of positive emotion, as revealed in previous studies (Haller \& Hadler, 2006; Stephens et al., 2012). Therefore, this study set the following hypothesis based on the previous research on authenticity and positive emotion and on the emotional contagion mechanism.

\section{$\mathrm{H}_{2}$ : Authenticity felt by SME employees is positively associated with positive emotion.}

\subsection{Positive emotions and affective commitment}

According to Staw and Barsade (1993), organizational members who experience more positive emotions engage in more social activities in the organization than those who do not. Fredrickson (2001) also claimed that positive emotion experienced by organizational members led to positive affect like emotional attachment and contributed to reducing the dysfunction of negative emotions like cynicism. Hatfield, Cacioppo, and Rapson (1993) argued that positive emotion experienced by organizational members could also be transferred to other members. Such positive emotion and positive affect turned out to have a positive effect on overall organizational effectiveness, job satisfaction, and affective commitment (George \& Brief, 1992). Weiss and Cropanzano (1996), drawing on the affective events theory, suggested that emotion and affect formed affective 
factors on job satisfaction and commitment when performing a task in the organization, arguing for a significant causal relationship between positive emotion and affective commitment. Therefore, previous studies on positive emotion revealed that those who were satisfied with their life and work made a higher affective commitment and job performance than those who were not. Likewise, Brief and Roberson (1989) revealed that organizational members' positive emotions over the last few weeks had a significant effect on their overall job satisfaction, and Fisher (2000) confirmed that emotions, positive affect, and negative affect were important antecedents of organizational performance. Furthermore, Lilius et al. (2008) empirically found that positive emotions had a significant positive effect on affective commitment. Therefore, this study set the following hypothesis based on the empirical research on positive emotion and affective commitment and on the affective events theory (Weiss \& Cropanzano, 1996).

\section{$H_{3}$ : Positive emotion formed in SME employees is positively associated with affective commitment.}

\subsection{Compassion and affective commitment}

Previous studies show that organizational members experiencing compassion built positive affect and thereby had a greater emotional attachment to their organization (Meyer \& Allen, 1991). According to the affective events theory, the act of experiencing compassion is perceived as an unusual emotional event, especially within the organization, and organizational members show great attachment to the organization as they build positive emotion (Weiss \& Cropanzano, 1996). Therefore, organizational members working at SMEs would regard compassion as a source of positive emotion, feel their pride in the organization, and think that their organization is a successful one (Cialdini et al., 1976). A positive idea of receiving emotional support like compassion in the organization reinforces organizational members' affective commitment to the organization (Rhoades, Eisenberger, \& Armeli, 2001). Furthermore, compassion also reinforces the feeling that organizational members are being cared for or valuably recognized by the organization, providing a driving force that makes organizational members become more affectively committed to the organization or organizational membership beyond their own identity (Meyer \& Allen, 1991). Finally, because compassion occurring within an organization often arise from its members who are struggling with work-related issues, compassionate behaviors not only help balance their lives and work but also reduce the risk of conflicts within the role and strengthen affective commitment (Allen, 2001). Therefore, this study hypothesized that compassion would have a positive effect on affective commitment based on previous studies that empirically examined the causal relationship between compassion and affective commitment.

\section{$H_{4}$ : Compassion experienced by SME employees is positively associated with affective commitment.}

\subsection{A double-mediation effect of authenticity and positive emotion on the relationship between compassion and affective commitment}

Compassion as an act of responding to the suffering of others is felt by organizational members as an authentic behavior (Kanov et al., 2004). Organizational members who experience compassion with others feel authenticity about the compassionate behavior because it is the nature of compassion that they are cognitively aware of and affectively feel the suffering of others and then respond to the suffering authentically and behaviorally (Stephens et al., 2012). Compassionate behaviors within an organization create a high-quality connection (HQC) among members, provoking positive emotions based on the emotional contagion mechanism (Schoenewolf, 1990). In other words, members who feel authenticity through others' compassionate behaviors within an organization gain joy, comfort, and hope for the members and the organization while sharing positive emotions (Barsade, 2002). Furthermore, organizational members who have formed positive emotions recognize the acts of giving and receiving compassion as an event. Based on the affective events theory mentioned by Weiss and Cropanzano (1996), positive emotions would enhance organizational members' affective commitment to performing their duties within the organization. Therefore, this study set the following hypothesis to test the double-mediation effect of authenticity and positive emotions on the relationship between compassion and affective commitment based on previous studies on the causal relationship among compassion, authenticity, positive emotion, and affective commitment. Figure 1 depicts our conceptual model.

$H_{5}$ : The relationship between compassion and affective commitment is double-mediated by authenticity and positive emotion in that order.

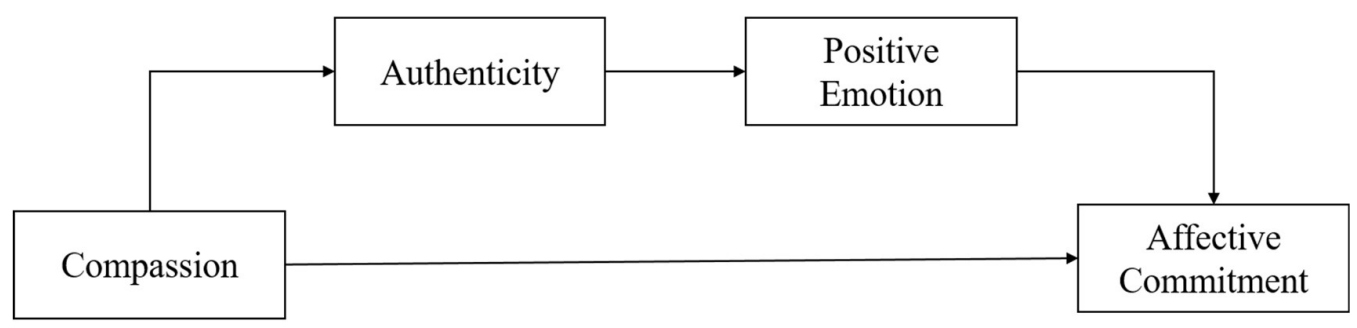

Fig 1. Conceptual model 


\section{Material and methods}

\subsection{Participants and procedures}

This study administered surveys with employees working at 10 SMEs located in South Korea. A total of 215 employees responded to the survey; excluding 15 surveys with insincere responses or with central tendency, 200 surveys were used for data analysis.

\subsection{Measurement}

\subsubsection{Compassion}

In this study, we define compassion as an act of responding to the suffering of others. We used three items developed by Lilius et al. (2008) to measure compassion: "I often experience compassion at my workplace," "I often experience compassion from my supervisor," "I often experience compassion from my colleagues." The items were measured on a 5-point Likert scale, and the scale reliability was acceptable (Cronbach's alpha $=0.765)$.

\subsubsection{Authenticity}

This study defines authenticity as an "intrinsic behavior arising from the heart." Five items used in the study by Price et al. (1995) were adapted to measure the construct of authenticity in this study (e.g., "I feel that organization members' compassionate behaviors are authentic," "I think that organizational members' compassionate behaviors reveal themselves"). The items were measured on a 5-point Likert scale, and the scale reliability was acceptable (Cronbach's alpha $=0.730$ ).

\subsubsection{Positive emotion}

In this study, positive emotion is defined as "the joyful, proud, and inspiring emotions experienced by organizational members," and four items used in Lilius et al. (2008) were employed to measure the construct of positive emotion (e.g., "I am proud of everything," "I am happy about everything"). The items were measured on a 5-point Likert scale, and the scale reliability was acceptable (Cronbach's alpha $=0.725)$.

\subsubsection{Affective commitment}

This study adopts the operational definition of affective commitment suggested by Allen and Meyer (1990): "Employees' emotional attachment to, identification with, and involvement in the organization." Five out of the eight measurement scales developed by Allen and Meyer (1990) were adapted to measure the construct of affective commitment in this study (e.g., "I feel 'emotionally attached' to my work in this organization," "I feel a strong sense of belonging to my organization"). The items were measured on a 5-point Likert scale, and the scale reliability was acceptable (Cronbach's alpha $=0.897$ ).

\subsubsection{Control variables}

We controlled the effects that demographic variables (age, education, religion, term of service, term of continuous service, income) might have on the constructs of compassion, authenticity, positive emotion, and affective commitment. Furthermore, we controlled other compounding effects that the propensity of individuals might have on the constructs.

\section{Results}

\subsection{Common method bias}

A cross-sectional study that measures independent and dependent variables simultaneously with self-reported responses may entail a bias (Podsakoff et al., 2003). A Harmon one-factor test (Podsakoff \& Organ, 1986) was conducted to see if the measurement involves a common method bias issue. The results showed the presence of four distinct factors with eigenvalue greater than 1.0, rather than a single factor, and the covariance explained by one factor was $19 \%$, indicating that the common method bias is not a serious concern (not a likely contaminant of the measurement) (Podsakoff \& Organ, 1986; Podsakoff et al., 2003).

\subsection{Results of confirmatory factor analysis}

The discriminant validity was verified by AVE (Average Variance Extracted), and the internal reliability was examined with Cronbach's alpha coefficients. Cronbach's alpha coefficients were greater than 0.7 , and AVEs were greater than 0.6 for all latent variables, meeting the traditionally recommended criteria. The $\chi 2$ estimate was significant $(\chi 2(80)=141.562 ; \mathrm{p}<.001)$. The CFA results are considered satisfactory and are presented in Table 1. 
Table 1

Confirmatory Factor Analysis Results

\begin{tabular}{ccccccc}
\hline & CFI & TLI & GFI & NFI & RMSEA & RMR \\
\hline CFA & .949 & .933 & .915 & .893 & .062 & .044 \\
\hline & \multicolumn{7}{c}{ Variables } \\
\cline { 2 - 7 } & Compassion & Authenticity & Positive Emotion & Affective \\
\hline AVE & .729 & .714 & .736 & .780 & \\
\hline
\end{tabular}

\subsection{Correlation Analysis and Validity Test}

Multicollinearity was checked before testing the hypotheses in the structural equation model. Pearson's coefficients were used to examine the correlations between latent variables. Regression analysis was conducted to check multicollinearity, and the results showed VIFs were between 1.117 and 1.291, indicating no serious multicollinearity issues. The results of the correlation analysis are shown in Table 2 below.

Table 2

Correlation Analysis Result

\begin{tabular}{llllll}
\hline & Mean & SD & 1 & 2 & \\
\hline 1. Compassion & 3.596 & .732 & .853 & & \\
2. AUT & 3.877 & .545 & $.289^{* *}$ & .844 & \\
3. PE & 4.133 & .554 & $.379^{* *}$ & $.404^{* *}$ & .857 \\
4. AC & 4.056 & .617 & $.326^{* *}$ & $.260^{* *}$ & $.221^{* *}$ \\
\hline
\end{tabular}

Note $:{ }^{*}<.05, * * p<.01,{ }^{* *} \mathrm{p}<.001$ The number in the diagonal is the square root of the AVE, AUT $=$ Authenticity, PE $=$ Positive Emotion, AC $=$ Affective Commitment

\subsection{Hypothesis testing: Path analysis}

\subsubsection{Path coefficients}

After confirmatory factor analysis, items with a low factor loading were removed from the model, resulting in three items for the construct of compassion, three items for authenticity, four items for positive emotion, and five items for affective commitment. The hypothesis test was based on this final set of measurement items. The model fit of the research model was verified through a confirmatory factor analysis. The results of confirmatory factor analysis for the measurement model are shown in Table 4, and the results of hypothesis testing are presented in Table 3. First, compassion experienced by SEM employees turned out to be positively and significantly associated with authenticity $(\beta=0.899, \mathrm{p}<0.01)$, confirming $H_{l}$. Authenticity was positively and significantly associated with positive emotion $(\beta=0.550, \mathrm{p}<0.01)$, so $\mathrm{H}_{2}$ is accepted. Third, positive emotion turned out to be positively and significantly associated with affective commitment $(\beta=0.535, \mathrm{p}<0.001)$, supporting $H_{3}$. Fourth, compassion was positively and significantly associated with affective commitment $(\beta=0.506, \mathrm{p}<$ 0.001 ), confirming $H_{4}$.

Table 3

Path Analysis Result

\begin{tabular}{|c|c|c|c|c|c|c|}
\hline $\mathrm{H}$ & Path & $\mathrm{b}$ & $\mathrm{SE}$ & $\mathrm{CR}$ & $\mathrm{P}$ & Test \\
\hline $\mathrm{H} 1$ & Compassion $\rightarrow$ Authenticity & .899 & .274 & 7.285 & $<.01$ & Accept \\
\hline $\mathrm{H} 2$ & Authenticity $\rightarrow$ PE & .550 & .261 & 8.112 & $<.01$ & Accept \\
\hline H3 & $\mathrm{PE} \rightarrow \mathrm{AC}$ & .535 & .188 & 9.335 & $<.001$ & Accept \\
\hline $\mathrm{H} 4$ & Compassion $\rightarrow \mathrm{AC}$ & .506 & .219 & 7.862 & $<.001$ & Accept \\
\hline
\end{tabular}

Note : $* * * p<.001 \mathrm{PE}=$ Positive Emotion, $\mathrm{AC}=$ Affective Commitment

Table 4

Confirmatory Factor Analysis Result

\begin{tabular}{ccccccc}
\hline & \multicolumn{1}{c}{ CFI } & TLI & GFI & NFI & RMSEA & RMR \\
\hline \multirow{3}{*}{ CFA } & .911 & .903 & .907 & .897 & .072 & .057 \\
\cline { 2 - 7 } & \multicolumn{2}{l}{$\chi^{2}(78)=216.851 ; p<.001$} & & & & \\
\hline
\end{tabular}

4.3.2 The double-mediation effect of authenticity and positive emotion on the relationship between compassion and affective commitment

The analysis of mediation effects has been widely used to clarify the causal relationship between latent variables in the field of business administration (Lee \& Choi, 2010), and regression analysis has been used in numerous studies to test mediation 
effects over the last 30 years (Lee \& Choi, 2010). However, the methods used to examine mediation effects in previous studies failed to adequately reflect measurement errors and have been known to have a limitation in examining complex and sophisticated mediation models such as a multi-mediation model or a double-mediation model (Luthans \& Youssef, 2007; Preacher \& Hayes, 2008). Ways to overcome the limitation of the conventional approach to examining mediation effects have been discussed. One of the most popular alternative ways to examine mediation effects is the 'Process' macro using bootstrapping. Bootstrapping is useful in determining whether indirect effects are statistically significant (CI95\% = LLCI value, ULCI value). Using bootstrapping, the indirect effect of authenticity and positive emotion on the relationship between compassion and affective commitment were between LL95CI $=0.006$ and UL95CI $=0.011$. Because zero (0) is not included in 95\% CI [.006, 0.011], the double-mediation effect was confirmed, supporting $H_{5}$.

Table 5

Indirect Effects for the Double-Mediation (Authenticity and Positive Emotion)

\begin{tabular}{|c|c|c|c|}
\hline \multirow[b]{2}{*}{ From $\rightarrow$ To } & \multicolumn{3}{|c|}{ Indirect Effects } \\
\hline & Estimate & CI low & CI high \\
\hline Total indirect effect & $.036(.050)$ & .014 & .096 \\
\hline Compassion $\rightarrow$ AUT $\rightarrow$ AC & $.024(.050)$ & .001 & .068 \\
\hline Compassion $\rightarrow \mathrm{PE} \rightarrow \mathrm{AC}$ & $.010(.071)$ & .031 & .052 \\
\hline Compassion $\rightarrow$ AUT $\rightarrow \mathrm{PE} \rightarrow \mathrm{AC}$ & $.002(.086)$ & .006 & .011 \\
\hline
\end{tabular}

\section{Conclusion}

\subsection{Summary of results}

This study empirically found that if SME employees experienced compassion in response to the mental and physical sufferings such as job stress and emotional exhaustion in the workplace, they would feel authenticity about the compassionate behaviors and form positive emotions, eventually leading to a stronger affective commitment to their organization. All hypotheses established in the study were supported, including the double-mediation effect of authenticity and positive emotion on the association between compassion and affective commitment.

\subsection{Implications}

First, this study provides a theoretical implication by empirically examining the causality of authenticity and positive emotion in the relationship between compassion and affective commitment, being differentiated from previous studies (Grandey, 2003). That is, the study empirically found that the relationship between compassion and affective commitment was significantly double-mediated by authenticity and positive emotion, contributing to the theories in this field. Second, the study provides a practical implication that by experiencing compassion as an act of caring in response to the suffering arising from excessive workloads and jobs stress, SEM employees would feel other organizational members' compassionate behaviors as being authentic and build positive emotions about the organization, eventually making a stronger affective commitment to the organization. Third, being differentiated from previous empirical studies by the Positive Organizational Scholarship (POS) on the relationships between compassion and performance variables, this study empirically examined the causal relationship of positive variables such as authenticity and positive emotion, providing a theoretical implication (Williams \& Anderson, 1991). Thus, this study provides a practical implication that when SME employees experience compassion in response to the suffering of other employees, they will contribute to forming a positive organizational culture in their company (Dutton, 2003; Frost, 2003).

\subsection{Limitations and future research directions}

First, this study collected the data from SME employees sampled in South Korea, having a limitation in generalizing the findings. More empirical studies with SME employees in different countries in diverse contexts are warranted for the generalization of the findings from this study. Second, in measuring compassion, this study used three items from the qualitative and quantitative studies by Dutton and his colleagues since the 1990s (Lilius et al., 2008). However, it is desirable to identify key dimensions of the compassion scale by conducting qualitative research through interviews with SME employees based on the grounded theory. Therefore, future studies will need to increase the validity of the compassion scale and develop a research model for empirical research based on the causal relationship of those key dimensions identified through qualitative research. Third, this study empirically examined the causal relationship of compassion with job performance as a dependent variable. Future studies, however, must follow to further examine the causal relationships of compassion with corporate social responsibility, rudeness, and other performance variables. Fourth, this study relied on cross-sectional data, which gives rise to a difficulty in establishing causal relationships between variables. For example, while a hypothesis implies a causal relationship that collective pride formed in employees would have an influence on job performance, a reverse causal relationship cannot be ruled out (i.e., job performance can cause collective pride). A longitudinal data collection is warranted for future research to overcome this limitation. 


\section{References}

Allen, N. J., \& Meyer, J. P. (1990). Organizational socialization tactics: A longitudinal analysis of links to newcomers' commitment and role orientation. Academy of Management Journal, 33(4), 847-858.

Allen, T. D. (2001). Family-supportive work environments: The role of organizational perceptions. Journal of Vocational Behavior, 58(3), 414-435.

Ashkanasy, N. M. \& Tse, B. (2000), Transformational leadership as management of emotions: A conceptual review. In N. Ashkanasy, C. Hartel, \& W. Zerbe (Eds.), Emotions in the workplace: Theory, research and practice (pp. 221-235). Westport, CT: Quorum.

Avolio, B. J. \& Mhatre, K. H.(2012), Advances in theory and research on authentic leadership. In K. S. Cameron, \& G. Spreitzer (Eds.). The Oxford handbook of positive organizational scholarship (pp. 773-783). New York: Oxford University Press.

Barsade, S. G. (2002). The ripple effect: Emotional contagion and its influence on group behavior. Administrative Science Quarterly, 47(4), 644-675.

Brief, A. P., \& Roberson, L. (1989). Job attitude organization: An exploratory study. Journal of Applied Social Psychology, 19(9), 717-727.

Cialdini, R. B., Borden, R. J., Thorne, A., Walker, M. R., Freeman, S., \& Sloan, L. R. (1976). Basking in reflected glory: Three (football) field studies. Journal of Personality and Social Psychology, 34(3), 366.

Dutton, J.E. (2003). Energize your workplace: How to build and sustain high-quality connections at work. San Francisco: Jossey-Bass.

Dutton, J. E., Frost, P. J., Worline, M. C., Lilius, J. M., \& Kanov, J. M. (2002). Leading in times of trauma. Harvard Business Review, 80(1), 54-61.

Fredrickson, B. L. (2001). The role of positive emotions in positive psychology: The broaden-and-build theory of positive emotions. American Psychologist, 56(3), 218-226.

Frost, P. J. (2003). Toxic emotions at work: How compassionate managers handle pain and conflict. Boston, MA: Harvard Business School Press.

Frost, P. J., Dutton, J. E., Worline, M. C., \& Wilson, A. (2000). Narratives of compassion in organizations. Emotion in Organizations, 2, 25-45.

George, J. M., \& Brief, A. P. (1992). Feeling good-doing good: a conceptual analysis of the mood at work-organizational spontaneity relationship. Psychological Bulletin, 112(2), 310-329.

Grandey, A. A. (2003). When "the show must go on": Surface acting and deep acting as determinants of emotional exhaustion and peer-rated service delivery. Academy of Management Journal, 46(1), 86-96.

Haller, M., \& Hadler, M. (2006). How social relations and structures can produce happiness and unhappiness: An international comparative analysis. Social Indicators Research, 75(2), 169-216.

Harvey, J. H. (2001). The psychology of loss as a lens to a positive psychology. American Behavioral Scientist, 44(5), 838853.

Hatfield, E., Cacioppo, J. T., \& Rapson, R. L. (1993). Emotional contagion. Current Directions in Psychological Science, 2(3), 96-100.

Hur, W. M., Moon, T., \& Rhee, S. Y. (2016). Exploring the relationships between compassion at work, the evaluative perspective of positive work-related identity, service employee creativity, and job performance. Journal of Services Marketing, 30(1), 103-114.

Ilies, R., Morgeson, F. P., \& Nahrgang, J. D. (2005). Authentic leadership and eudaemonic well-being: Understanding leaderfollower outcomes. The Leadership Quarterly, 16(3), 373-394.

Kanov, J. M., Maitlis, S., Worline, M. C., Dutton, J. E., Frost, P. J., \& Lilius, J. M. (2004). Compassion in organizational life. American Behavioral Scientist, 47(6), 808-827.

Lee, D.S., \& Choi, Y. D. (2010). A study on antecedents and consequences of positive psychological capital in organizations. Korean Management Review, 39(1), 1-28.

Lilius, J. M., Worline, M. C., Maitlis, S., Kanov, J., Dutton, J. E., \& Frost, P. (2008). The contours and consequences of compassion at work. Journal of Organizational Behavior: The International Journal of Industrial, Occupational and Organizational Psychology and Behavior, 29(2), 193-218.

Luthans, F., \& Youssef, C. M. (2007). Emerging positive organizational behavior. Journal of Management, 33(3), $321-349$.

Meyer, J. P., \& Allen, N. J. (1991). A three-component conceptualization of organizational commitment. Human Resource Management Review, 1(1), 61-89.

Michie, S., \& Gooty, J. (2005). Values, emotions, and authenticity: Will the real leader please stand up? The Leadership Quarterly, 16(3), 441-457.

Miller, K. I. (2007). Compassionate communication in the workplace: Exploring processes of noticing, connecting, and responding. Journal of Applied Communication Research, 35(3), 223-245.

Moon, T. W., Hur, W. M., Ko, S. H., Kim, J. W., \& Yoon, S. W. (2014). Bridging corporate social responsibility and compassion at work: Relations to organizational justice and affective organizational commitment. Career Development International, 19(1), 49-72.

Podsakoff, P. M., \& Organ, D. W. (1986). Self-reports in organizational research: Problems and prospects. Journal of Management, 12(4), 531-544. 
Podsakoff, P. M., MacKenzie, S. B., Lee, J. Y., \& Podsakoff, N. P. (2003). Common method biases in behavioral research: A critical review of the literature and recommended remedies. Journal of Applied Psychology, 88(5), 879-903.

Preacher, K. J., \& Hayes, A. F. (2008). Asymptotic and resampling strategies for assessing and comparing indirect effects in multiple mediator models. Behavior Research Methods, 40(3), 879-891.

Price, L. L., Arnould, E. J., \& Deibler, S. L. (1995). Consumers' emotional responses to service encounters: the influence of the service provider. International Journal of Service Industry Management, 6(3), 34-63.

Reich, W. T. (1989). Speaking of suffering: A moral account of compassion. Soundings, 83-108.

Rhoades, L., Eisenberger, R., \& Armeli, S. (2001). Affective commitment to the organization: The contribution of perceived organizational support. Journal of Applied Psychology, 86(5), 825-836.

Schoenewolf, G. (1990). Emotional contagion: Behavioral induction in individuals and groups. Modern Psychoanalysis, 15(1), 49-61.

Solomon, R. C. (1998). The moral psychology of business: Care and compassion in the corporation. Business Ethics Quarterly, 8(3), 515-533.

Staw, B. M., \& Barsade, S. G. (1993). Affect and managerial performance: A test of the sadder-but-wiser vs. happier-andsmarter hypotheses. Administrative Science Quarterly, 38(2), 304-331.

Stephens, J. P., Heaphy, E., \& Dutton, J. E. (2012), High quality connections. In K. S. Cameron, \& G. Spreitzer (Eds.). The Oxford handbook of positive organizational scholarship (pp. 385-399). New York: Oxford University Press.

Walumbwa, F. O., Avolio, B. J., Gardner, W. L., Wernsing, T. S., \& Peterson, S. J. (2008). Authentic leadership: Development and validation of a theory-based measure. Journal of Management, 34(1), 89-126.

Weiss, H. M., \& Cropanzano, R. (1996). Affective events theory: A theoretical discussion of the structure, causes and consequences of affective experiences at work. In B. W. Staw \& L. L. Cummings (Eds.), Research in organizational behavior (Vol. 19, pp. 1-74). Greenwich, CT: JAI Press.

Williams, L. J., \& Anderson, S. E. (1991). Job satisfaction and organizational commitment as predictors of organizational citizenship and in-role behaviors. Journal of Management, 17(3), 601-617.

Wuthnow, R. (1991). Acts of compassion: Caring for others and helping ourselves. Princeton, NJ: Princeton University Press.

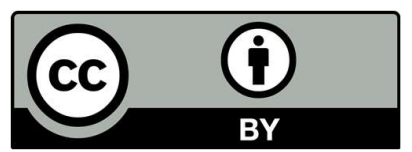

(C) 2020 by the authors; licensee Growing Science, Canada. This is an open access article distributed under the terms and conditions of the Creative Commons Attribution (CC-BY) license (http://creativecommons.org/licenses/by/4.0/). 